\title{
DIGITAL TOOLS FOR THE KNOWLEDGE AND ENHANCEMENT OF WWII HERITAGE. The case study of Bosa in the west coast of Sardinia (Italy)
}

\author{
A. Pirinu ${ }^{1 *}$, R. $\operatorname{Argiolas~}^{1}$, N. Paba ${ }^{1}$ \\ ${ }^{1}$ DICAAR, University of Cagliari - apirinu@unica.it
}

KEY WORDS: digital database, integrated survey, WWII military heritage, costal landscape, Sardinia, Italy.

\begin{abstract}
:
The essay shows some results of a research aimed at building a digital database of Sardinian military architectures of Second World War. Following an activity of cataloguing entrusted to integrated digital survey methods already applied in other case studies of the region, this contribute analyses the built heritage placed in territory of Bosa, a centre located in the west coast of the island, in which 33 bunkers have been founded, most of them represented in the IGM military historical maps.

These "modern sentinels", positioned along the coastline, the main roads and the railway leading to the actual urban context, are designed in reinforced concrete, also integrated with local stone, with a frequently use of square and circle shape often combined or modified and adapted to achieve a complete mimesis in the landscape that hosts them.

The survey, applied at architecture and landscape scale, has produced a complete collection of data functional to realize an interoperable digital database, a necessary tool for a deepened knowledge and enhancement of a lost WWII heritage.
\end{abstract}

\section{INTRODUCTION}

Sardinian coastal landscape is characterized by "modern wars" heritage consisting of sixteenth century towers and bunker of the Second World War. This condition offers the opportunity to build a digital database functional to the knowledge and enhancement of the WWII works that, unlike the ancient towers, are not subject to protection and restoration projects.

The census of existing models favors the construction of a stylistic repertoire and a comparison with archival documents and with the works made in other contexts as the Mediterranean coast of Spain (Martínez-Medina 2016).

Fundamental tool for the collection of information is the $3 \mathrm{D}$ survey that allows to represent the architectural and landscape heritage. To do this is essential to define documentation strategies that select procedures and instruments, planning the operational phases and the levels of information aimed to the construction of a multidisciplinary and implementable 3D information system, for management, maintenance, and enhancement of architectural and landscape assets within cultural routes (Parrinello et al., 2019). The selection and structuring of data are therefore an essential step which facilitates the use of the database (Toniolo et al., 2015).

The structure of the SIT must contain the data deemed useful and, where possible, foresee future implementations.

The acquisition of data can be supported by digital survey methodologies; among these the use of photogrammetry with drones is widely used; their technological advancement makes them tools that, while maintaining relatively high-performance levels, allow to contain costs. High mobility allows drones to have access to areas that are inaccessible to humans, both in physical and environmental terms and to shoot at high altitudes from different point of view, making extremely easy to work in very large areas, as well as on individual emergencies.

All of these qualities, combined with the possibility of flight planning and the high mobility of cameras mounted on drones, make them instruments of exceptional flexibility of use.

The fields of use are multiple: from stratigraphic documentation to static and structural analysis, with the possibility of switching from architectural to territorial scale (Fiorillo et al., 2015) and represent the landscape transformation. The information acquired through the photogrammetric survey can be supported by instrumental survey and GPS references and integrated by direct measurements and frames at the ground level with the possibility of acquiring detailed information on the dimensional and material characteristics that will compose the datasheet of the single bunker. The digital models thus obtained through the processing of data become part of an interoperable database that can be interrogated to obtain alphanumeric reports and twodimensional and three-dimensional drawings.

\section{STATE OF ART}

Knowledge creation is fundamental to understand and interpret cultural heritage and a multidisciplinary approach is needed when dealing with it (Berto et al., 2017). This aim requires a coordinated approach between the various actors, and systems are needed to integrate the various competences involved.

In addition, heritage knowledge is now an indispensable part of everyday life, not only in purely cultural but also in economic and social spheres; an example is the role that collecting and communicating this knowledge plays in the tourism and experiential sectors (Ruhanen \& Whitford, 2019).

The importance of knowing how to manage and preserve the built heritage is such that these aspects also become an integral and crucial part of strategic tools for the enhancement of the territory; the Strategic Plan for the Development of Tourism 2017-2022 defined by the Italian Minister for Cultural Heritage is an emblematic example. It is therefore evident that it is essential to think of tools capable of managing the enormous amount of data coming from multiple disciplines (Amato et al., 2017), each contributing to the creation of a knowledge framework as comprehensive as possible. Among the information regarding the heritage, the information concerning the various operations that involve and modify the heritage cannot be disregarded (Rinaudo et al., 2007), both in the past life and in the future of the artefacts. The need to collect information come with the need to be able to plan the

\footnotetext{
* Corresponding author
} 
management of the built heritage both from the point of view of its maintenance and safeguarding, and from the point of view of its recovery and re-functionalization. The ability to manage information becomes even more important in cases where information is large and complex. This is the case of point clouds resulting from laser scanner surveys or photogrammetric systems; these survey methods allow an enormous amount of spatial and chromatic information to be captured in a short time, at the cost of relatively long post-processing times. Although these systems often achieve comparable levels of precision, photogrammetry is a much more convenient tool in terms of cost and, above all, flexibility of use.

In particular, drone photogrammetry is increasingly being used when accessibility to the sites to be surveyed is severely limited; the causes that reduce accessibility can be either physical, preventing the operator from reaching the artefact to be surveyed, or environmental, due for example to chemical or biological risk conditions (Westoby et al., 2012). For these reasons the use of drones allows, with relatively low costs, surveys of rather high quality (Brumana et al., 2013; FernándezHernandez et al., 2015).

Acquired the information, to be used profitably, it is also essential to guarantee its accessibility. An established tool in this sense is the geodatabase, able to contain spatial and structured information (Malinverni et al., 2019); through these tools it is possible not only to facilitate the management and consultation of data, but also their implementation by different subjects at different times.

However, accessibility and use are deeply linked to the sharing of a single language among the various users and editors of the database; to make it possible, there is a need to create and adopt shared standards to standardise aspects such as definitions or information formats. In this sense, there are numerous contributions that analyse and propose different ways of standardising information (Corns \& Shaw, 2010; Fernándezfreire et al., 2013). There are also numerous examples of possible systems for the creation of information systems (Costantino et al., 2020; Veenendaal et al., 2017).

The choice is obviously strictly determined by the purposes which the information system is created for and thus by the type of system itself. If GIS is by now the universally recognised tool for working with geographic and spatial information, when communication and information sharing have a central role, one of the most used solutions is certainly that of Web-GIS systems (Figure 1); it can be considered to all effects a true evolution of the classic GIS (Baker, 2015), implementing the potential offered by web tools in terms of information exchange, but also for its analysis and communication. All the factors analysed so far are some of the reasons why Web-GIS tools are increasingly playing a decisive role in the cognitive processes involving the built historical heritage; in fact, each step of these processes can benefit from the possibilities that Web-GIS systems offer, from the knowledge gathering phases, to the analysis phases, up to the management, preservation, and valorisation phases (Costantino et al., 2020; Dolce et al., 2019; Vandenbulcke \& Decock, 2016)

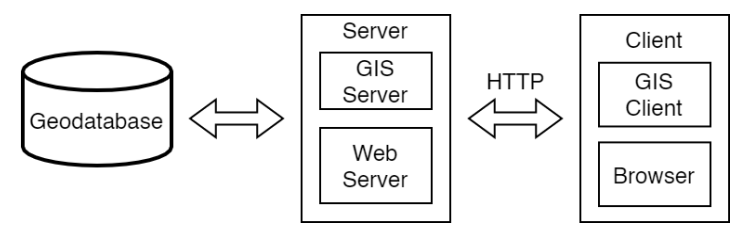

Figure 1. WebGIS Architecture.

\section{METHODOLOGY}

The definition of the methodology is closely linked to the aims to be achieved. As already mentioned, the proposed information system is intended to support the communication, valorisation and preservation of the architectures surveyed.

We have therefore opted for a methodology that is as synthetic and flexible as possible, capable of being improved or extended if the need arises in the future. In order to avoid limitations caused by the cost of the instruments, both physical and software, the use of low-cost technologies was favoured, capable of guaranteeing the necessary quality in the various operations (Sun \& Zhang, 2018). The use of more expensive equipment is not, as we shall see, excluded but limited to cases of particular interest or with particular needs. The process followed can be schematised into five macro-categories (Figure 2), of which the first three will be analysed in this contribution, while the fourth and fifth, data input and communication, are currently being developed.

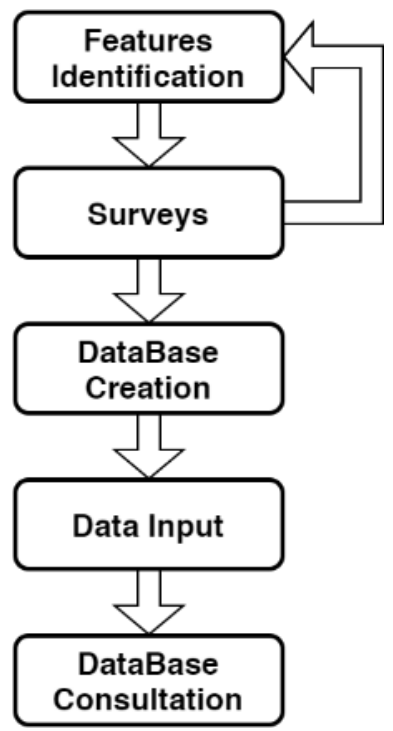

Figure 2. Figure placement and numbering.

The first phase is the identification of the features that our database must contain. The features will have to be such as to describe exhaustively not only the asset analysed as a physical object but will have to give a framework as complete as possible from a landscape, typological-functional and regulatory point of view. For this reason, it was decided to use two main classes of characteristics, those proper to the asset and those of the environment in which the artefact is inserted (Vacca et al., 2018). Among the characteristics we can cite the position, the materials, the state of conservation or even any constraints on it, as well as the historical and/or cartographic documentation.

The environmental characteristics include the accessibility of the site, the naturalistic information of the area, the intended use of the land or its typology. These will be followed by a whole series of information on the relationship with other anthropic elements, such as the presence of infrastructures or architecture in the vicinity, distances from inhabited centres and so on.

A possible schematisation of the database structure is shown in Figure 3. The data to be included in the database come mainly from three sources: historical-archival documentation, surveys of the artefacts and spatial analyses. 


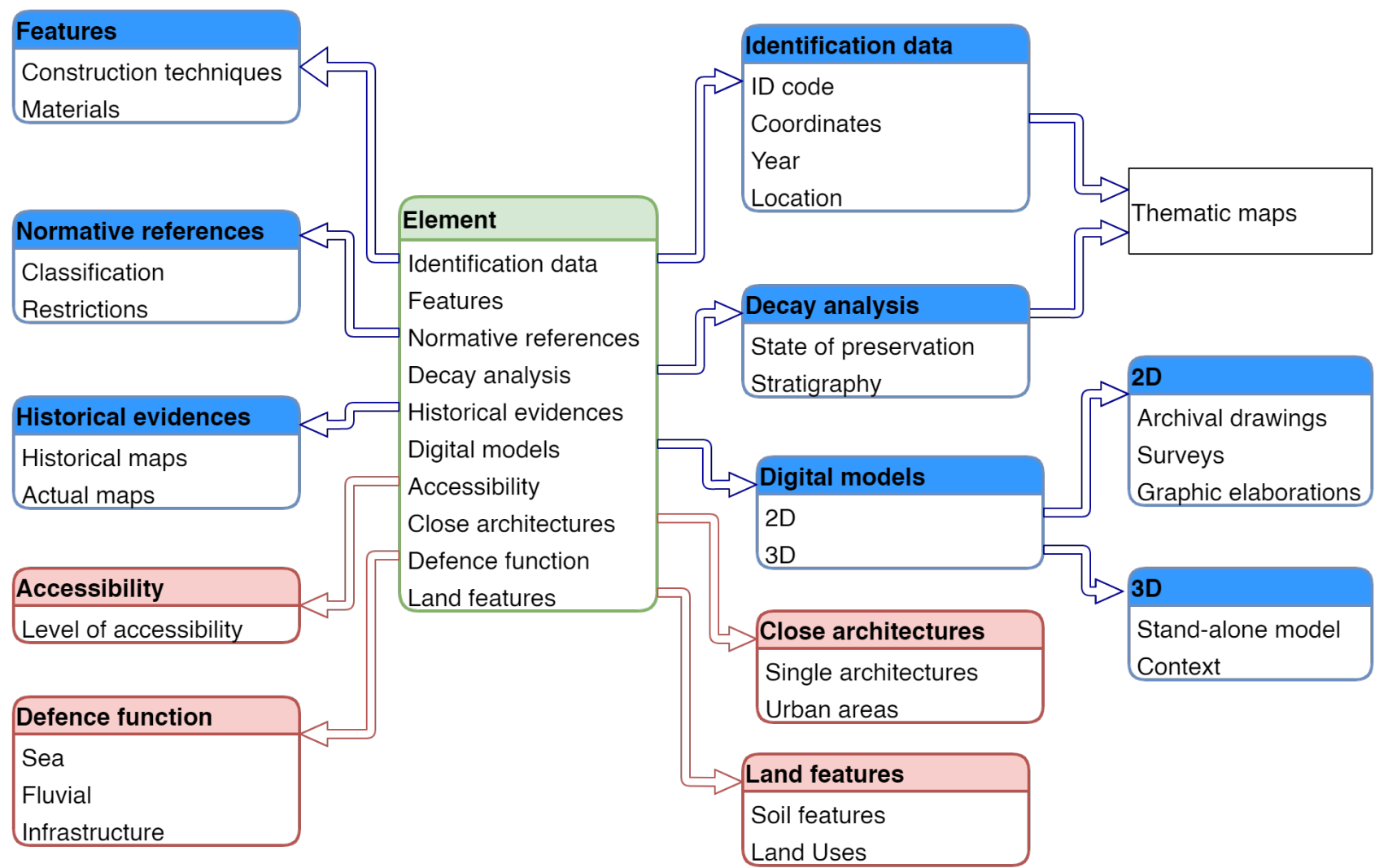

Figure 3. Schematization of the structure of the database.

\subsection{Survey}

Survey operations have required an integrated methodology in which direct measurements were supported by photogrammetric surveys at close range, both from the ground and by drone.

The drone survey was of fundamental importance since, by their nature, bunkers are often built in areas that are difficult to access, making ground survey operations difficult or impossible. In addition to solving the problem of accessibility (Westoby et al., 2012), the drone survey allows for a large area to be surveyed, which is crucial given our aims, while maintaining a relatively low time and cost of execution, in line with our objectives for this project. In cases of particular value, where the site permits, further integration by laser scanning is envisaged. The survey images were processed with the photogrammetric software Metashape, from which it was possible to obtain the point clouds and meshes at the basis of the dimensional, typological, and geometric analyses.

\subsection{Geodatabase}

The geodatabase, the core of the information system, was developed in parallel with the survey phases.

Having to work with information of different nature, including spatial information, and having the need not only to collect but also to manage and analyse such information, the choice of using GIS tools is now almost taken for granted. These tools have in fact established themselves for their ability to facilitate the management of a considerable amount of information through a single database, in addition to the considerable possibilities offered in the analytical field, spatial and otherwise (Agapiou et al., 2015; Guzzetti et al., 2010).
Today, there are numerous tools, more or less advanced, for the creation and management of geodatabases. Among the free options on the market, QGIS has proved to be particularly effective and versatile in numerous studies (Malinverni et al., 2019). Nevertheless, it was decided to build the database using PostgreSQL and its expansion for spatial data PostGIS, a tool considered more suitable for the structuring of a database that in the future will be implemented in a WebGIS system.

QGIS software was used to simplify database queries and to perform analyses. Since the number of case studies, and consequently the amount of information, was limited in this first phase of the research, it was decided to use QGIS to carry out the data entry phases as well.

\subsection{Communication of information}

The next step, currently in the development phase, involves the creation of separate web-based interfaces for data entry and consultation. At present, an initial analysis of the tools that can be used for the creation and management of the interaction interfaces between users and the database has been carried out; remaining faithful to the intention of using free, or at least lowcost, tools, it has been decided to create the dialogue components with the database using the PHP language, flanked for the creation of the interfaces by the classic HTML, Javascript and CSS languages. As far as Javascript is concerned, the Leaflet library for the creation of navigable and interactive maps will be of particular interest; Leaflet is in fact currently the tool chosen for the future development of the Web-GIS platform that will be created for consulting the information contained in our database. 


\section{CASE STUDIES}

The methodology has been applied to the system of bunkers designed to protect the city of Bosa and its territory following a first reconnaissance performed in the same area with photogrammetric methods and the use of a drone (MartínezMedina, Pirinu 2018, Pirinu et al., 2020). In these area 33 bunkers have been identified. The models, mainly built with reinforced concrete with shapes and dimensions in accordance with the archival documents, are distributed along the provincial roads that connect the city of Bosa with the territory, along the railway track Macomer-Bosa and the coast, at the entrance of the port to control the port and the mouth of the river Temo. In relation to assigned task the bunkers are isolated or grouped and the construction characteristics, such as the thickness of the perimeter walls, may be different from what is prescribed in the documents produced by the Military Engineers; this is evident for the small pillboxes present in the area of Columbargia, near the ancient Spanish tower, which have a masonry thickness of $45 \mathrm{~cm}$ and a weakly reinforced concrete combined with local stone, unlike bunkers located close to the city centre, built with a thickness of reinforced concrete walls of $1.40 \mathrm{~m}$, constructive characteristics that determine in the first case a clear state of degradation. Starting from an analysis of the IGM maps kept at the Historical Archive (AUSMEE, Rome) all of the artefacts identified have been catalogued with the acquisition of the information provided by the survey sheet (Figure 4). Field operations required the integration of the photogrammetric method and traditional survey for the documentation of individual bunkers and landscape context (Figure 5); in particular, the data collected with direct survey have been used for the preparation of an abacus of plans and shapes adopted. The photogrammetric survey instead required photographic shots from the ground (inside and outside the individual artefacts) and aerial shots with drone and aimed at the production of digital models.

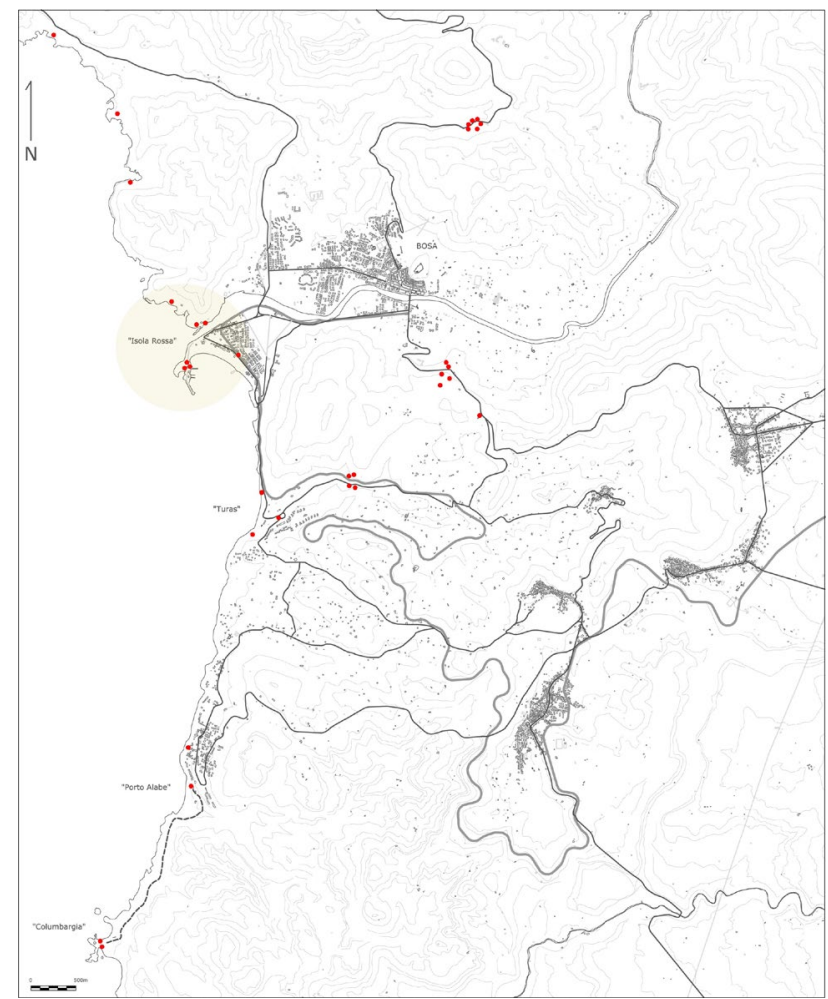

Figure 4. Location of bunkers on a georeferenced map.
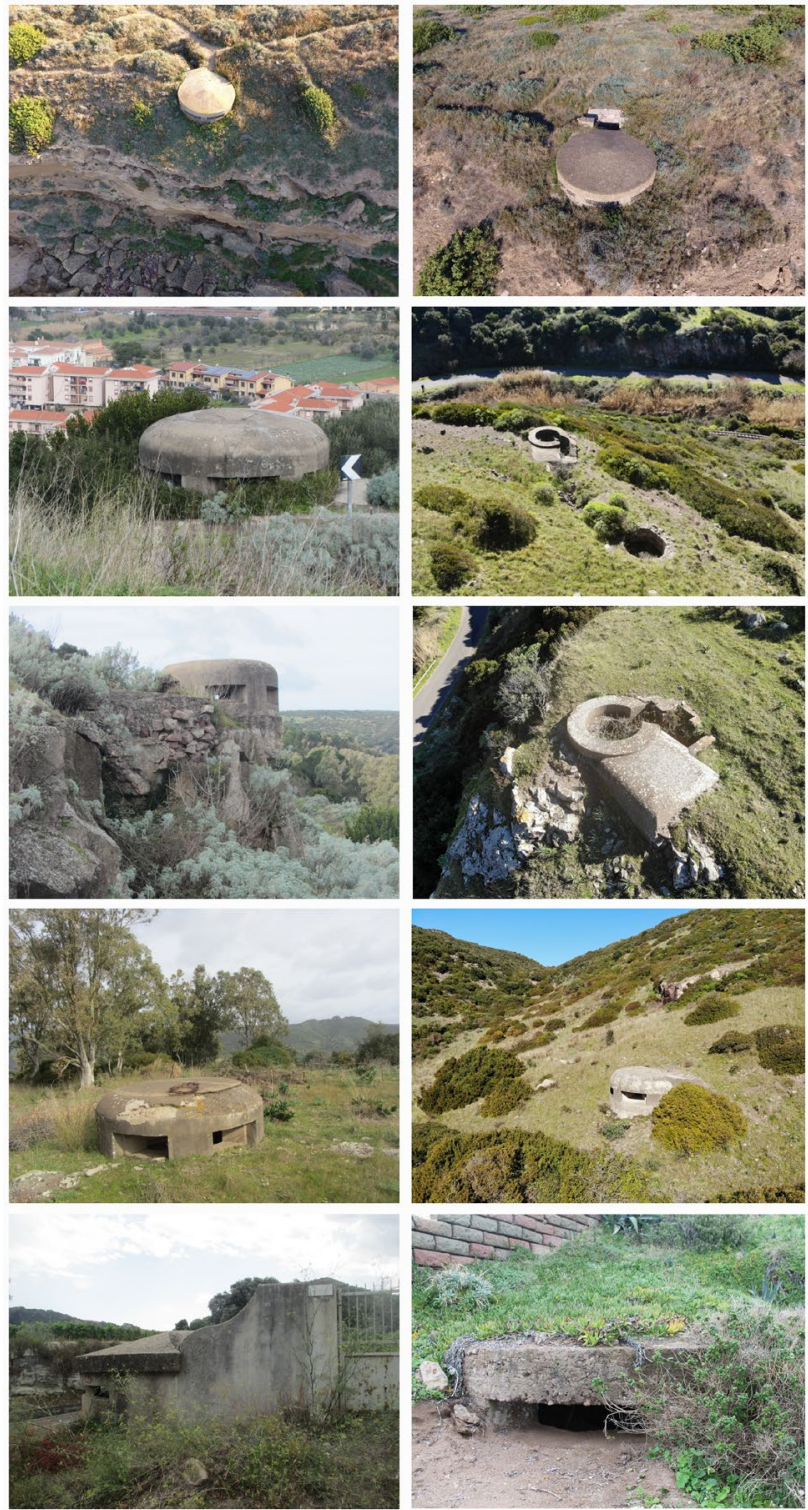

Figure 5. Some examples of bunkers built in Bosa territory.

\section{APPLICATION OF THE METHODOLOGY}

The survey has interested an area characterized by an articulated landscape context that determined different design choices to ensure mimesis and control of the territory (Figure 6).

Among different case studies the "Isola rossa" system is of particular interest. Since the mid-sixteenth century it has been guarded by a tower erected by the Spanish and enriched, during the IIWW, by a series of small bunkers designed to define a system of control of the port and the mouth of the river Temo. This site condition requires tools and methods capable of documenting the entire defensive system at the scale of architecture and landscape and contribute to the construction of the digital database.

Since it is however planned to extend the case studies, the implementation of these tools was made considering the possibility of encountering in the future case studies of particular interest and which may require the use of additional tools, such as the use of laser scanners for completely buried structures or built with traditional techniques (Figure 7). 


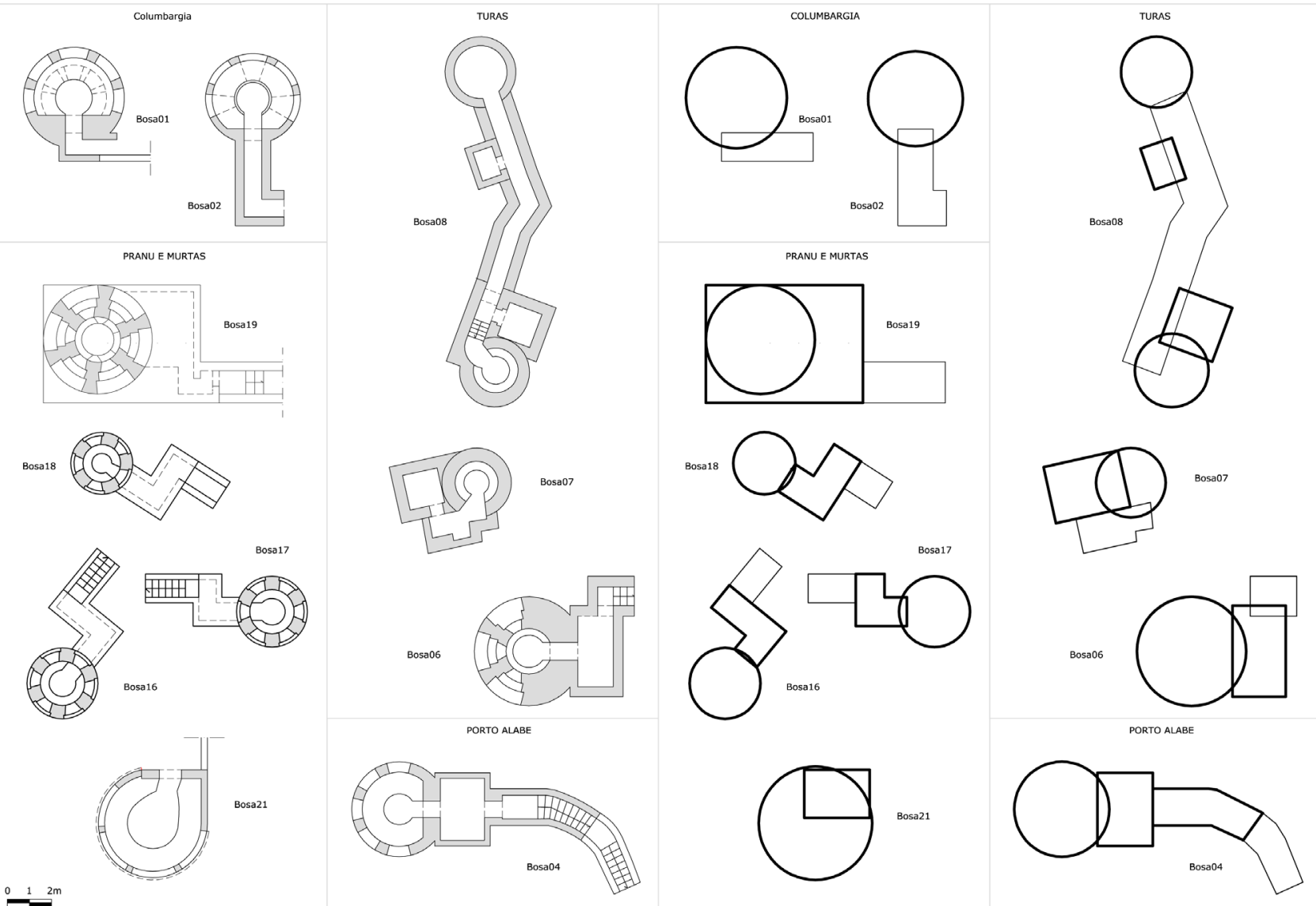

Figure 6. Abacus of several plans and shapes that can be found in the territory of Bosa.
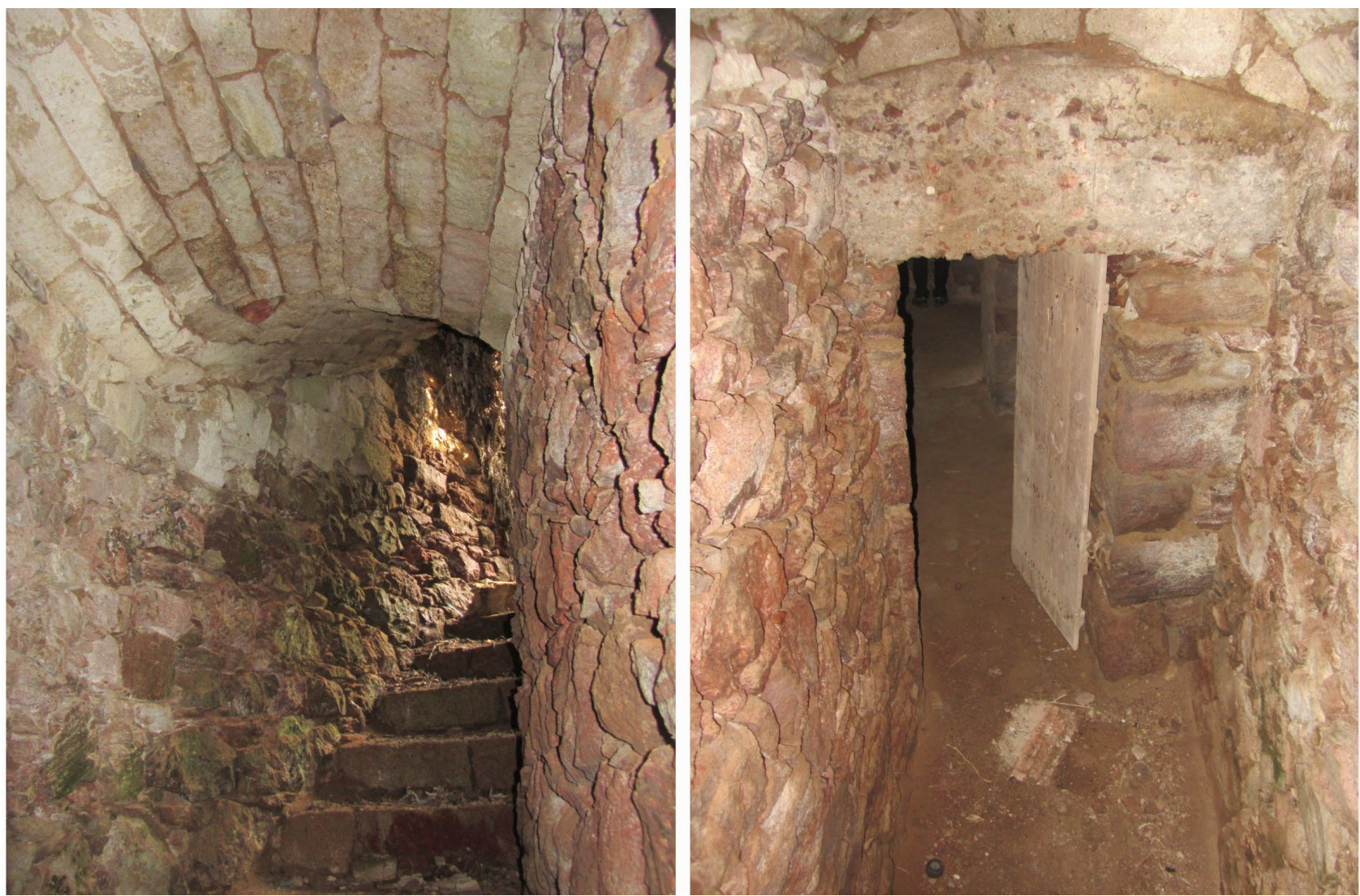

Figure 7. Underground vaulted passage located in the Porto Alabe Beach (Tresnuraghes). The structure, built with local stone, is particularly interesting for the use of traditional techniques integrated with the reinforced concrete. 


\subsection{The Survey and representation of the Isola Rossa defensive system}

For the survey of the Isola Rossa system, it was used a DJI Spark drone with flight plan at a constant height of 60 meters and parallel stripes at a distance of 38 meters, cruising speed $7.08 \mathrm{~m} / \mathrm{s}(25.50 \mathrm{~km} / \mathrm{h})$ and a travel interval of 4 seconds, such as to guarantee a lateral overlap of $55 \%$ and a longitudinal one close to $55 \%$. A camera equipped with a $1 / 2.3$ " sensor with a $4: 3$ aspect ratio and a resolution of $12.4 \mathrm{Mpx}$ was used to run the frames. The lens is equipped with a FOV (Field-of-View) of 94, equivalent to $25 \mathrm{~mm}$ (compared to the $35 \mathrm{~mm}$ format). The flight characteristics has determined an area of investigation is 84.69 $\mathrm{m} \times 63.52 \mathrm{~m}$ with a pixel resolution on the ground (GSD) of 2.1 $\mathrm{cm} /$ pixel.

The nadiral photos were supplemented by oblique ones taken at an appropriate height to document the sides of the promontory and another series of aerial photographs of the bunkers and the tower, taken at an altitude lower than these. The shots from the drone have been completed by images taken on the ground level; these ones, for the extremely lower shooting distance, ensure a definition consistent with a reproduction of the elaborate at architectural scale.

At this stage, a Sony ILCE-7M2 mirror less camera was used, equipped with a $36 \times 24 \mathrm{~mm}$ Full-Frame format sensor, with an aspect ratio of $3: 2$ and a resolution of $24 \mathrm{Mpx}$ with a Laowa Zero-D $12 \mathrm{~mm}$ wide-angle fixed focal length and a maximum aperture $F / 2.8$. The images were captured outside and inside of the small bunkers, with the aim of obtaining a high overlap between the shots and a complete three-dimensional model.

The field operations were followed by data processing. Once the images suitable for the photogrammetric method have been selected, the SfM process with software Agisoft Metashape has been carried out with which -starting from the recognizable elements- have been defined matching points that have produced a scattered cloud; this cloud has been analyzed and processed to allow a correct alignment of all images used during the process.

In particular, special care was taken to ensure that the images of the exterior and interior were aligned in a single chunk, in order to avoid alignment and scaling on the dense cloud. The scattered clouds obtained as a result of the SfM process, net of treatment and optimization, measure for the whole Isola Rossa 886.000 points, for the tower 188.000 , while for the single bunker 1.413 .885 points. Subsequently, we moved to the calculation of the dense cloud -that become part of the database- obtaining for the Isola Rossa 59.000 .000 points, for the tower 8.200.000 points and for the bunker 151.000 .000 points. The point clouds were then elaborated with the software CloudCompare.

The result is a digital model (Figure 8) aimed at highlighting the design choices at the time of the conflict and today useful for the enhancement of the cultural heritage by means the creation of a cultural itinerary guaranteed by the preservation of the historical and visual paths that connect the existing architectures.
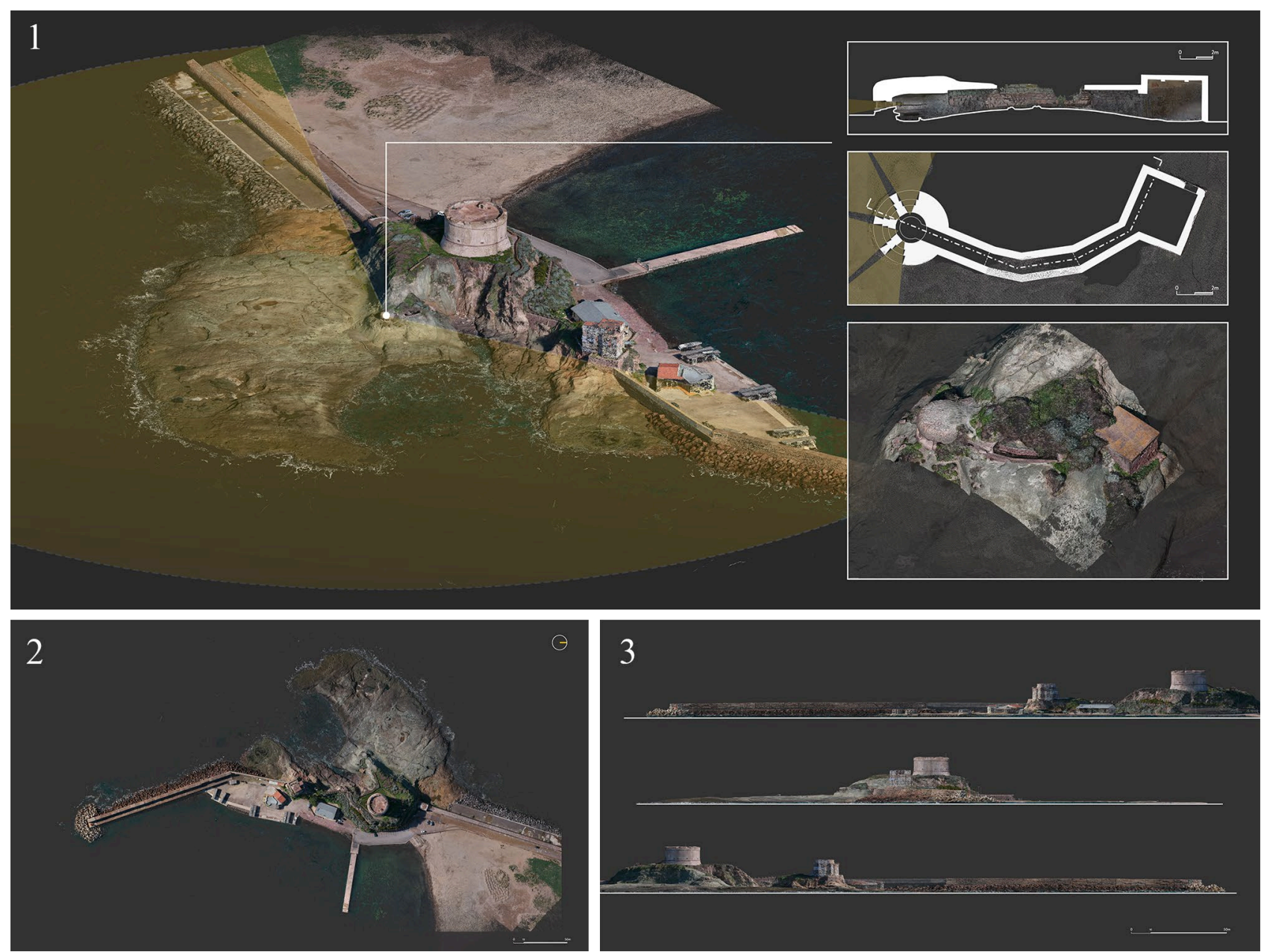

Figure 8. 1 - Digital model of the Isola Rossa and detail of the bunker positioned to control the entrance to the port, 2 - Orthophoto of the Isola Rossa, 3 - Environmental sections of the Isola Rossa along the NS axis and along the EW axis. 


\subsection{Database implementation}

At the same time as the survey operations, the database was created according to the scheme described above. PostgreSQL software was used to create and manage the database. In addition to the normal relational database management system (DBMS) functions of PostgreSQL, it is possible to add new spatial functions to allow the management and use of geometries and reference systems within the same database. The transformation from DBMS to geodatabase is possible thanks to the PostGIS extension of PostgreSQL.

Every aspect of the system is entirely managed by the SQL language, from the creation phase to the modification or query of the database; the pgAdmin tool, a GUI (Graphic User Interface) under PostgreSQL License, was used to facilitate these operations. As we have seen, in this phase of the research the database is organised according to a filing of the main characteristics of the individual artefact and the context in which it is located. In order to avoid misspellings or subjective nomenclatures, for the parameters that can be shared by several elements, such as materials, shapes or defensive function, we opted for the creation of a list of predetermined entries; this list, initially formed by the entries necessary to describe the current case studies and any others planned, can obviously be implemented as soon as a new case study makes it necessary. The adoption of pre-compiled lists has obvious advantages especially with regard to database queries, as they allow the elimination of multiple entries for the same parameter.

\section{RESULTS AND FURTHER RESEARCH}

The activity of cataloguing the models present in the territory of Bosa has highlighted the conservation of a control network that can be recovered and enhanced. The application of modern survey techniques to the scale of individual architectures and landscape and the support of digital tools have contributed significantly to the construction of a georeferenced and implementable database, capable of producing and manage summary sheets (Figure 9), thematic maps, two-dimensional and three-dimensional models of bunkers and the context in which they are inserted, sometimes inaccessible due to environmental conditions or state of degradation of the structures.

The result obtained is a further step in a path that provides a complete reconnaissance of military architecture built in Sardinia during the 1942 and contributes to their knowledge and dissemination and offers the necessary information for their protection and enhancement. In terms of representation and communication, the use of drones has in turn allowed the production of models of the landscape interoperable and usable also on the web favouring knowledge and therefore attention and awareness to the recovery of these "stubborn ruins", witnesses of a recent past.

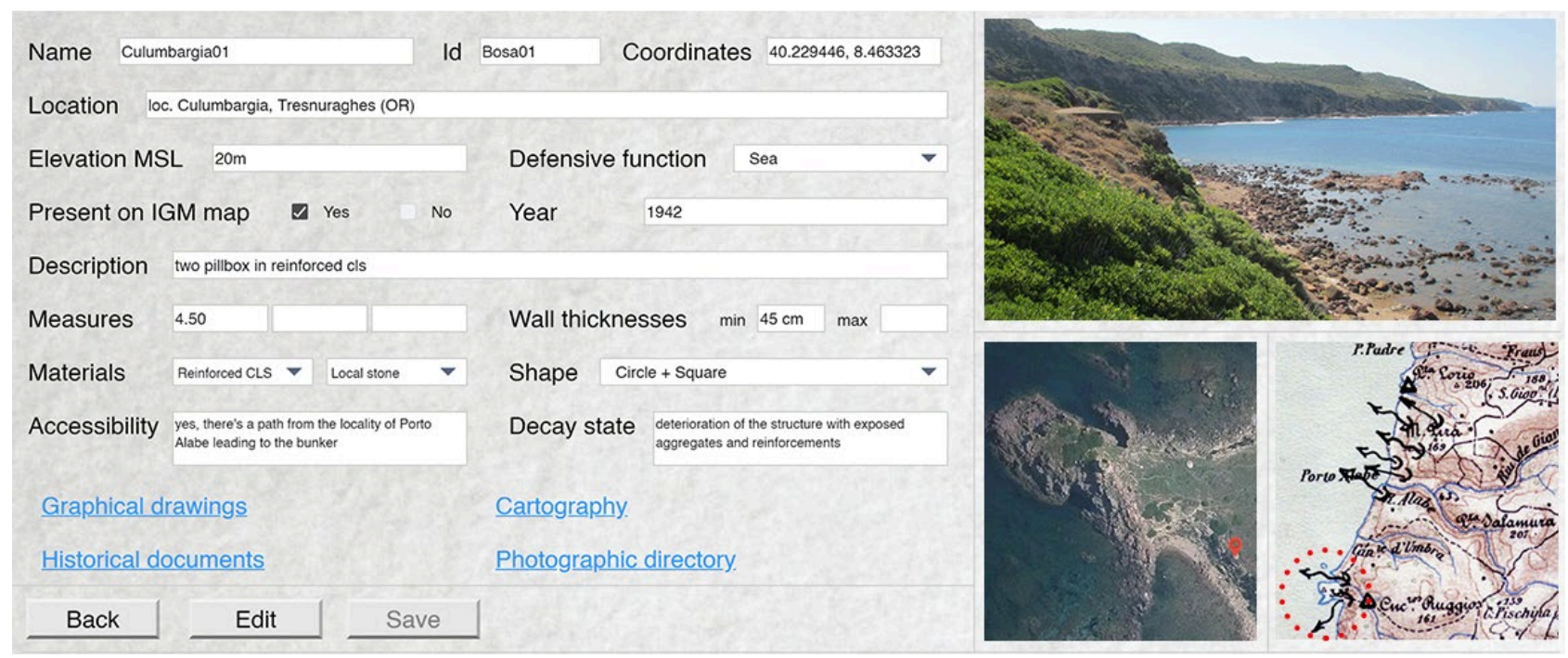

Figure 9. A preliminary propose for summary sheet for querying or editing of database data.

\section{ACKNOWLEDGEMENTS}

The authors thank to Salvatore Ganga (Archetypon) for his qualified contribution during survey operation with drone in the area of Turas and Columbargia.

\section{REFERENCES}

Agapiou, A., Lysandrou, V., Alexakis, D. D., Themistocleous, K., Cuca, B., Argyriou, A., Sarris, A., \& Hadjimitsis, D. G. (2015). Cultural heritage management and monitoring using remote sensing data and GIS: The case study of Paphos area, Cyprus. Computers, Environment and Urban Systems, 54, 230 239. https://doi.org/10.1016/j.compenvurbsys.2015.09.003
Amato, F., Moscato, V., Picariello, A., Colace, F., Santo, M. D., Schreiber, F. A., \& Tanca, L. (2017). Big Data Meets Digital Cultural Heritage: Design and Implementation of SCRABS, A Smart Context-awaRe Browsing Assistant for Cultural EnvironmentS. Journal on Computing and Cultural Heritage, 10(1), 6:1-6:23. https://doi.org/10.1145/3012286

Baker, T. R. (2015). WebGIS in Education. In O. Muñiz Solari, A. Demirci, \& J. Schee (A c. Di), Geospatial Technologies and Geography Education in a Changing World: Geospatial Practices and Lessons Learned (pagg. 105-115). Springer Japan. https://doi.org/10.1007/978-4-431-55519-3_9 
Berto, L., Doria, A., Faccio, P., Saetta, A., \& Talledo, D. (2017). Vulnerability Analysis of Built Cultural Heritage: A Multidisciplinary Approach for Studying the Palladio's Tempietto Barbaro. International Journal of Architectural Heritage, 11(6), 773-790. https://doi.org/10.1080/15583058.2017.1290853

Brumana, R., Oreni, D., Van Hecke, L., Barazzetti, L., Previtali, M., Roncoroni, F., \& Valente, R. (2013). Combined geometric and thermal analysis from UAV platforms for archaeological heritage documentation. ISPRS Annals of the Photogrammetry, Remote Sensing and Spatial Information Sciences, II-5/W1, 4954. https://doi.org/10.5194/isprsannals-ii-5-w1-49-2013

Corns, A. J., \& Shaw, R. (2010). Cultural Heritage Spatial Data Infrastructures (SDI) - Unlocking the Potential of our Cultural Landscape Data. 8.

Costantino, D., Angelini, M. G., Alfio, V. S., Claveri, M., \& Settembrini, F. (2020). Implementation of a system WebGIS open-source for the protection and sustainable management of rural heritage. Applied Geomatics, 12(1), 41-54. https://doi.org/10.1007/s12518-019-00275-6

Dolce, M., Speranza, E., Giordano, F., Borzi, B., Bocchi, F., Conte, C., Di Meo, A., Faravelli, M., \& Pascale, V. (2019). Observed damage database of past Italian earthquakes: The Da.D.O. WebGIS. Bollettino di Geofisica Teorica ed Applicata, 60(2), 141-164. https://doi.org/10.4430/bgta0254

Fernández-freire, C., Del-bosque-gonzález, I., Vicent, J. M., Pérez-asensio, E., Fraguas-bravo, A., Uriarte, A., Fábregaálvarez, P., \& Parcero-oubiña, C. (2013). A Cultural Heritage Application Schema: Towards Interoperability of Cultural Heritage Data in INSPIRE.

Fernández-Hernandez, J., González-Aguilera, D., Rodríguez-Gonzálvez, P., \& Mancera-Taboada, J. (2015). Image-based modelling from unmanned aerial vehicle (UAV) photogrammetry: an effective, low-cost tool for archaeological applications. Archaeometry, 57(1), 128-145.

Fiorillo, F., Jiménez Fernández-Palacios, B., Remondino, F., \& Barba, S. (2015). 3D Surveying and modelling of the Archaeological Area of Paestum, Italy. Virtual Archaeology Review, 4(8), 55-60.

Guzzetti, F., Viskanic, P., Cattaneo, N., Di Maria, F., \& Privitera, A. (2010). Specifiche tecniche per la realizzazione del database topografico del patrimonio verde. https:/www.r3gis.com/sites/default/files/Specifiche $\% 20$ tecniche $\% 20 \mathrm{del} \% 20 \mathrm{ve}$ rde.pdf

Malinverni, E. S., Chiappini, S., \& Pierdicca, R. (2019). A geodatabase for multisource data management applied to cultural heritage: the case study of Villa Buonaccorsi's historical garden. ISPRS - International Archives of the Photogrammetry, Remote Sensing and Spatial Information Sciences, XLII-2/W11, 771-776. https://doi.org/10.5194/isprsarchives-XLII-2-W11-771-2019

Martínez-Medina, A., Pirinu, A. (2018). Entre la tierra y el cielo. Arquitecturas de la guerra en Cerdeña: un paisaje a conservar. Between earth and sky. War architecture's in Sardinia: a landscape to preserve. ArcHistoR, 11, 2018, pp.88125, https://doi.org/10.14633/AHR116
Parrinello, S., Picchio, F., De Marco, R., \& Dell'Amico, A. (2019). Documenting the cultural heritage routes. The creation of informative models of historical russian churches on upper kama region. The International Archives of the Photogrammetry, Remote Sensing and Spatial Information Sciences, XLII-2/W15, 887-894. https://doi.org/10.5194/isprsarchives-xlii-2-w15-887-2019

Pirinu, A. Argiolas, R., Paba, N. (2020). UAVs and photogrammetry for landscape analysis of Sardinia's "modern wars architectures", Prospettive Multiple. Studi di Ingegneria, Architettura e Arte, Pavia University Press, pp. 306-315.

Pirinu, A., Martínez-Medina, A., Paba, N. (in press). Towards a digital database of Sardinian II WW military heritage: a first repertoire in the territory of Cagliari. Acta Imeko.

Rinaudo, F., Agosto, E., \& Ardissone, P. (2007). GIS and WebGIS, commercial and open source platforms: general rules for cultural heritage documentation. 7.

Ruhanen, L., \& Whitford, M. (2019). Cultural heritage and Indigenous tourism. Journal of Heritage Tourism, 14(3), 179 191. https://doi.org/10.1080/1743873X.2019.1581788

Sun, Z., \& Zhang, Y. (2018). Using Drones and 3D Modeling to Survey Tibetan Architectural Heritage: A Case Study with the Multi-Door Stupa. Sustainability, 10(7), 2259. https://doi.org/10.3390/su10072259

Toniolo, L., Boriani, M., \& Guidi, G. (Eds.). (2015). Built Heritage: Monitoring Conservation Management. Research for Development. Springer. https://doi.org/10.1007/978-3-31908533-3

Vacca, G., Fiorino, D. R., \& Pili, D. (2018). A Spatial Information System (SIS) for the Architectural and Cultural Heritage of Sardinia (Italy). ISPRS International Journal of Geo-Information, 7(2), 49. https://doi.org/10.3390/ijgi7020049

Vandenbulcke, A. (2016). Preservation of the archaeological heritage of the north sea using WebGIS. 16th International Multidisciplinary Scientific GeoConference SGEM2016, Informatics, Geoinformatics and Remote Sensing. https://doi.org/10.5593/sgem2016/b23/s11.048

Veenendaal, B., Brovelli, M. A., \& Li, S. (2017). Review of Web Mapping: Eras, Trends and Directions. ISPRS International Journal of Geo-Information, 6(10), 317. https://doi.org/10.3390/ijgi6100317

Westoby, M. J., Brasington, J., Glasser, N. F., Hambrey, M. J., \& Reynolds, J. M. (2012). 'Structure-from-Motion' photogrammetry: A low-cost, effective tool for geoscience applications. Geomorphology, 179, 300-314. https://doi.org/10.1016/j.geomorph.2012.08.021 